\title{
Role of religious organizations in forming social awareness of rural population in Assiut governorate, Egypt
}

\author{
Ibrahim I. R. S. , Khalifa I. A. A., Abo Elenein M. A. \\ Department of Agricultural Extension and Rural Sociology, Faculty of Agriculture, Al-Azhar University, Assiut, Egypt
}

\begin{abstract}
The objective of this search is: Identify the role of religious organizations in forming social awareness of rural population in the research area. Identify the level of implementation of religious organizations for their role in forming social awareness of the rural population in the research area. Identify the level of benefit of the respondents from the role of religious organizations in forming social awareness of the rural population in the research area. Study the relationship between the level of implementation of religious organizations for their role in forming social awareness and between the independent variables studied. Study the relationship between the level of benefit of the respondents from the role played by religious organizations in forming social awareness and between the independent variables studied. The research was conducted in five villages in Assiut governorate. Data were collected from random sample of 378 family. a prepared questionnaire used to collect data from lord of families' personal interviews. Frequencies, percentages, spearman correlation coefficient, chi square test, were used for data presentation and analysis using SPSS program. The results showed that: The results showed that the level of implementation of religious organizations for their role in forming social awareness average. The results showed that the level of benefit of the respondents from the role played by religious organizations in forming social awareness is average. There is a relationship between the level of implementation of religious organizations for their role in forming social awareness, and the level of benefit of the respondents from the role played by religious organizations in forming social awareness and between some independent variables at levels 0.01 , and 0.05 .
\end{abstract}

Keywords: the role, religious organizations, social awareness, rural population, Assiut.

* Corresponding author: Ibrahim I. R. S.,

E-mail address: thebird1_82@yahoo.com 


\title{
دور المنظمات الدينية في تشكيل الوعي الاجتماعي للسكان الريفيين بمحافظة أسيوط بجمهورية مصر العربية الاعيماعية
}

\author{
إسماعيل رستم سلام إبر اهيم ، إبر اهيم عبد الرحمن علي خليفة ، مصطفى عبد الحميد أبو العنين \\ قسم الارشاد الزر اعى والمجتمع الريفي ، كلية الزراعة ، جامعة الأزهر (فرع أسيوط) ، أسيوط ، جمهورية مصر العربية
}

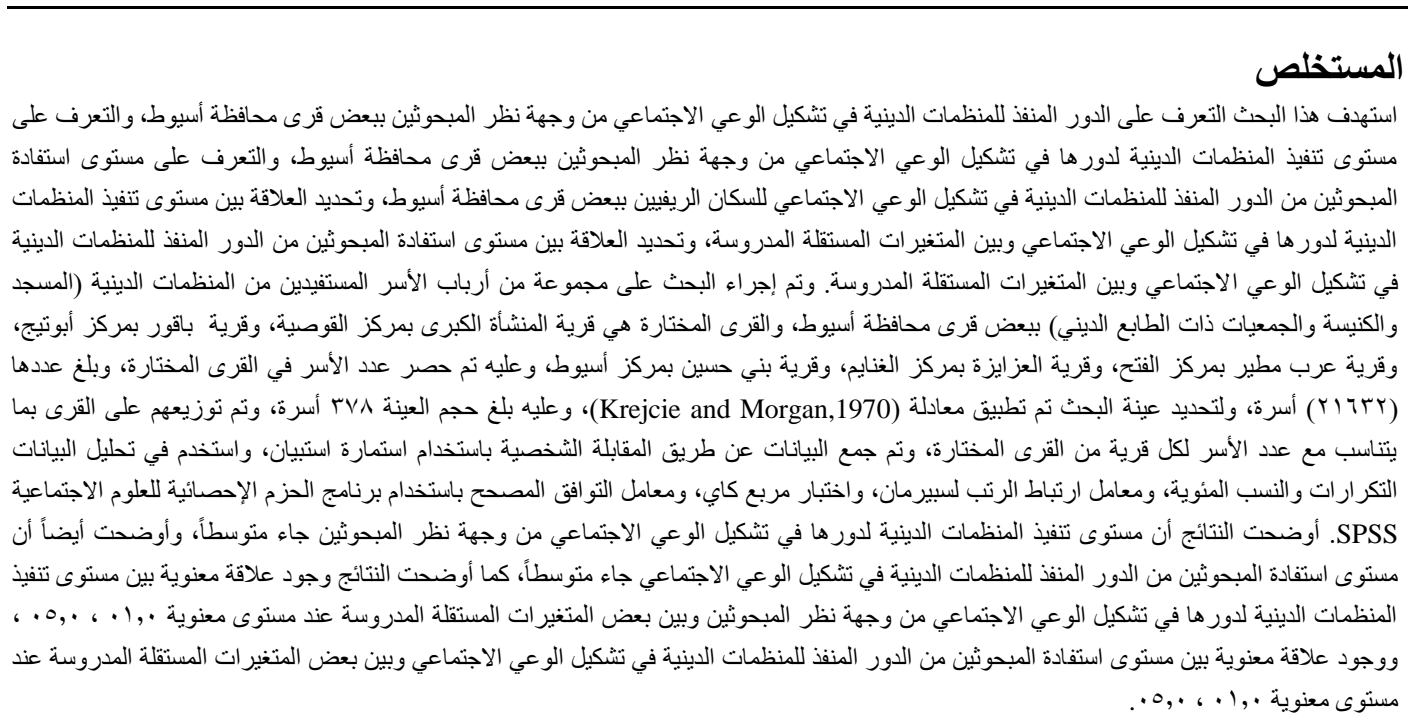

كلمات دالة: الدور، المنظمات الدينية، الوعي الاجتماعي، السكان الريفيين، أسيوط. 
المجتمع واستمر ارها (Hinings and Raynard, 2014).

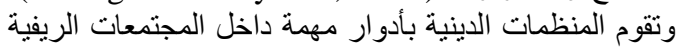

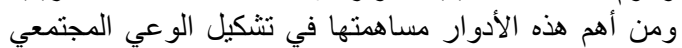

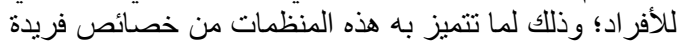

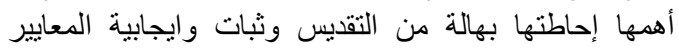

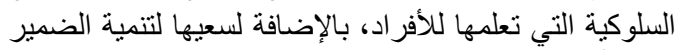

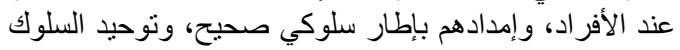

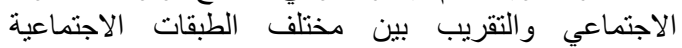

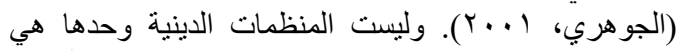

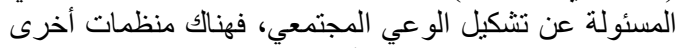

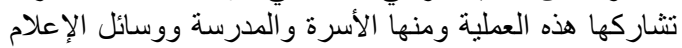

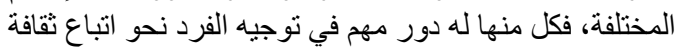

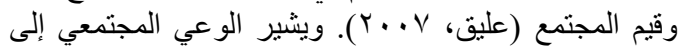

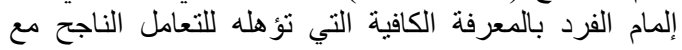

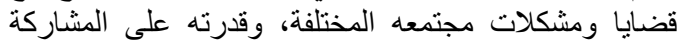

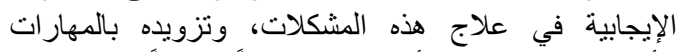

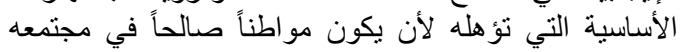

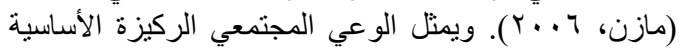

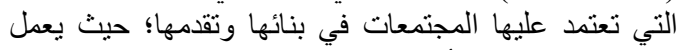

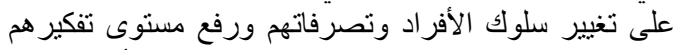

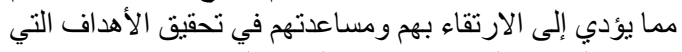

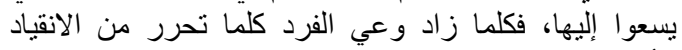

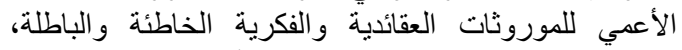

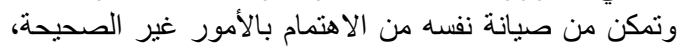

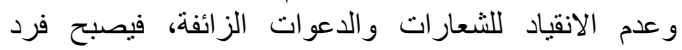

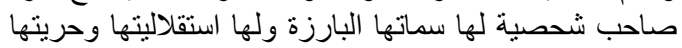

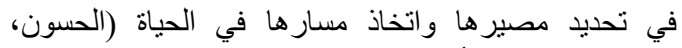

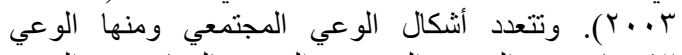

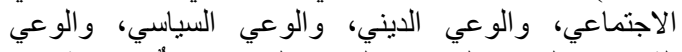

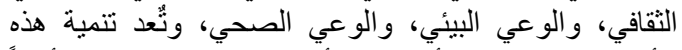

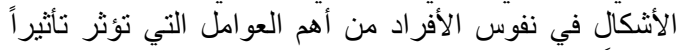

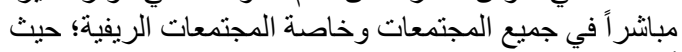

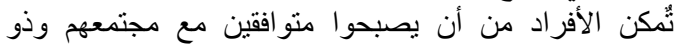

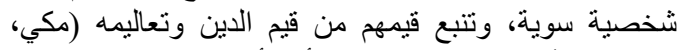

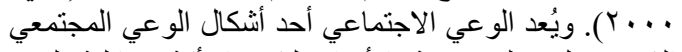

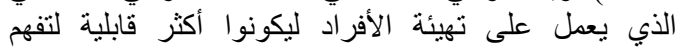

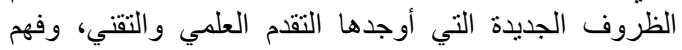

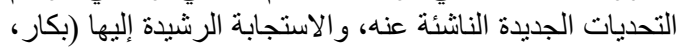
الوع ب...

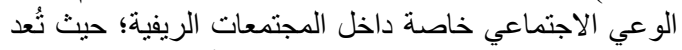

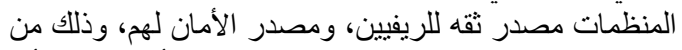

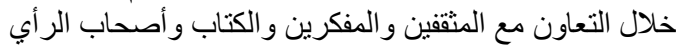

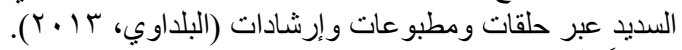

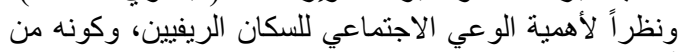

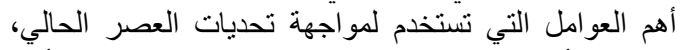
وركيزة أساسية في تنمية المجتمع والحفاظ على على أمنه

\section{مقدمة ومشكلة البحث}

تُّد دراسة السكان من المحاور الرئيسية التي تتبع منها العديد

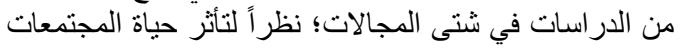

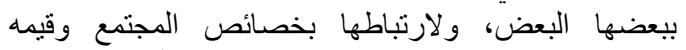

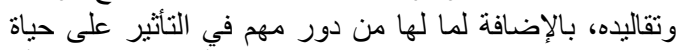

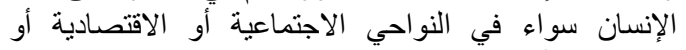

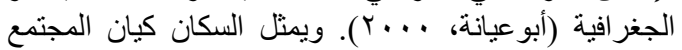

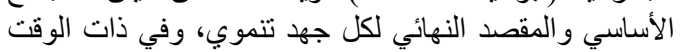

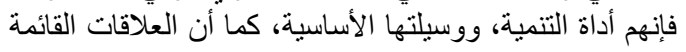

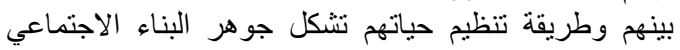

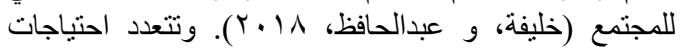

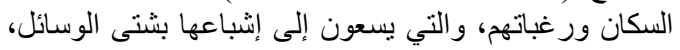

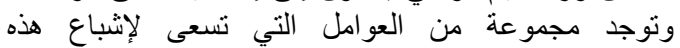

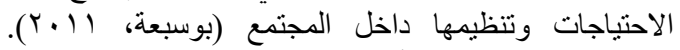

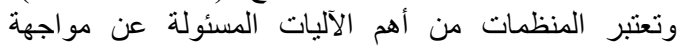

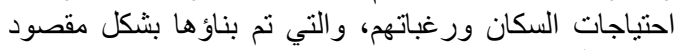

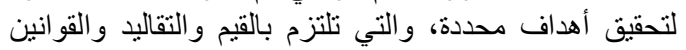

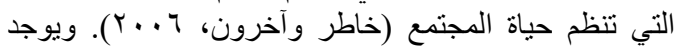

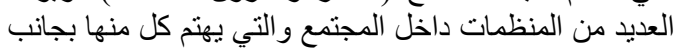



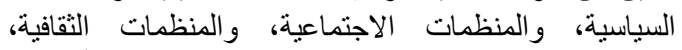

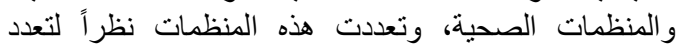

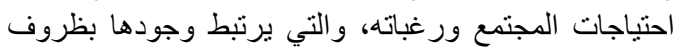

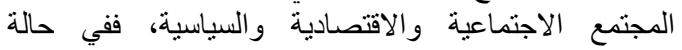

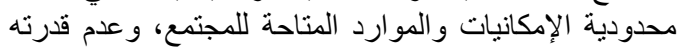

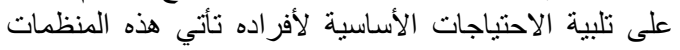

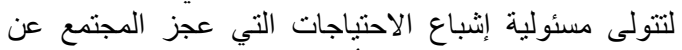

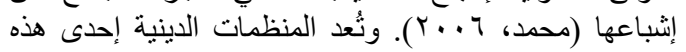

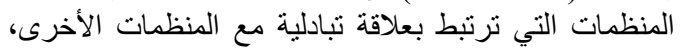

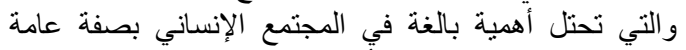

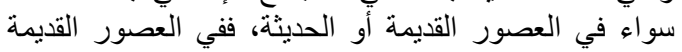

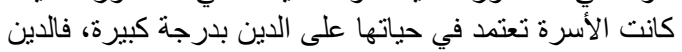

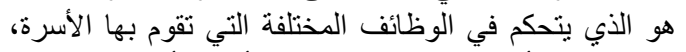

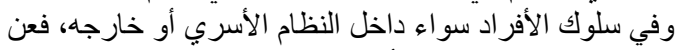

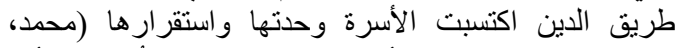

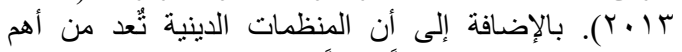

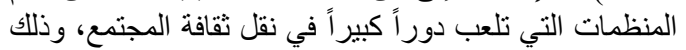

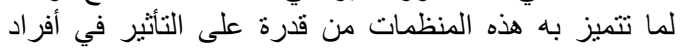

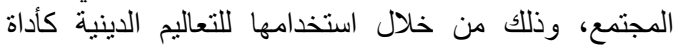
للوصول إلى الناس، وتعليمهم، وغرس القيم الدينية الصحيحة

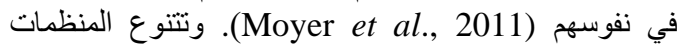

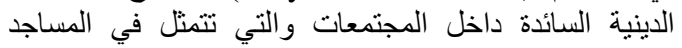

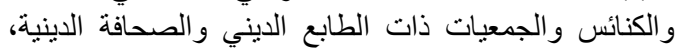

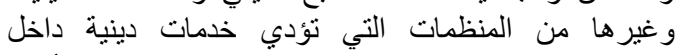
المجتمعات، والتي تساعد في بقاء التحياة الاجتماعية لأفراد 
Ibrahim et al. / Archives of Agriculture Sciences Journal 4(2) 21-32, 2021.

مجتمعهم، وفهمهم للأحداث الاجتماعية المختلفة التي تحدث بالمجتمع.

\section{فروض البحث}

لتحقيق الهافين الرابع و الخامس من أهداف البحث نم صياغة الفروض البحثية التالية: - اليع

ا. لورجد علاقة بين مستوى تنفيذ المنظمات الدينية

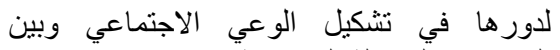
المتغير ات ألمستقلة المدروسة.

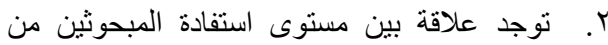

الدور المنفذ للمنظمات الدينية في تنشكيل الوعي الوني

الاجتماعي وبين المتغير ات المستقلة المدروسة.

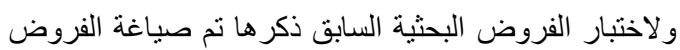

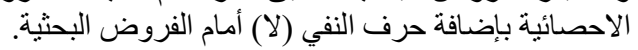

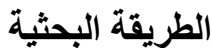

نم اختبار محافظة أسيوط كنطاق جغرافي لإجراء البحث،

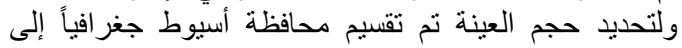

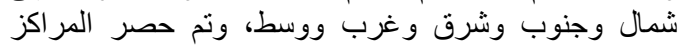

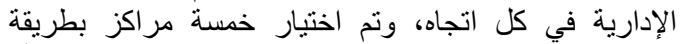

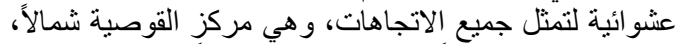

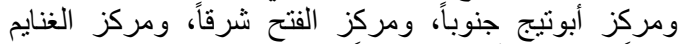

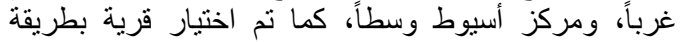

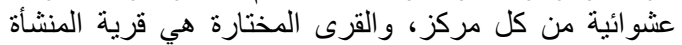

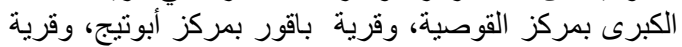

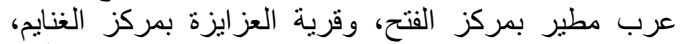

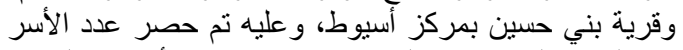

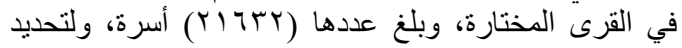

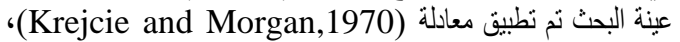

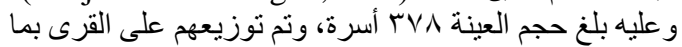

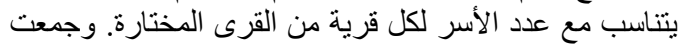

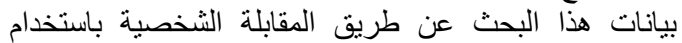

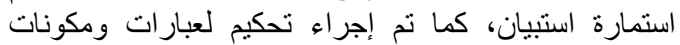

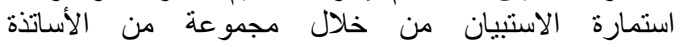
المتخصصين في علم الاجتماع الريفي والإرشاد الزئن الزراعي

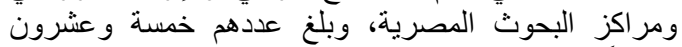

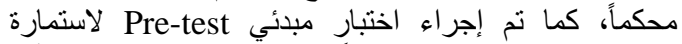

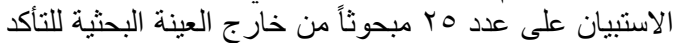

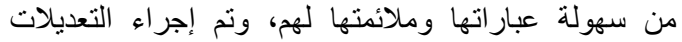

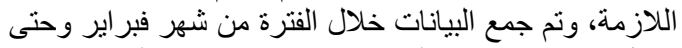

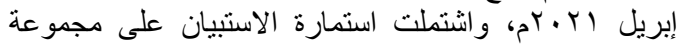

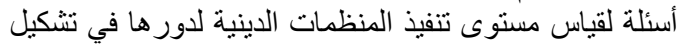

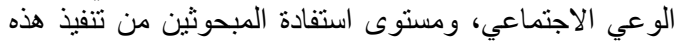

الادوار بمنطقة البحث (جدول () ).
واستقراره، ولذا فإن دراسة الوعي الاجتماعي ومدى تأثره

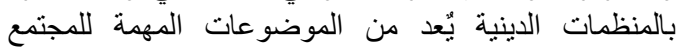

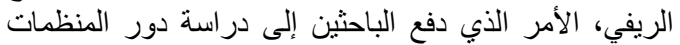

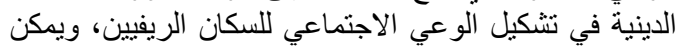

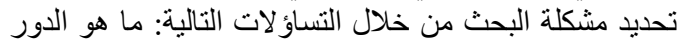

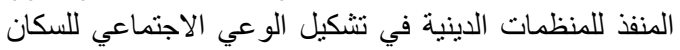

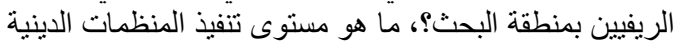

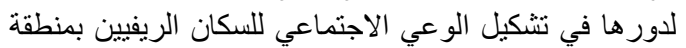

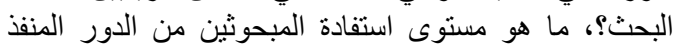

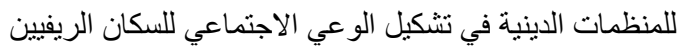

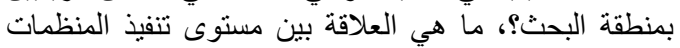

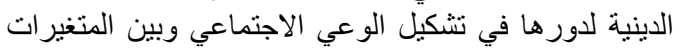

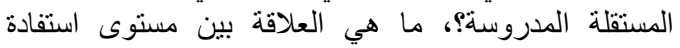
المبحوثين من الدور المنفذ للمنظمات الدئين الدينية في تشكيل الوعي

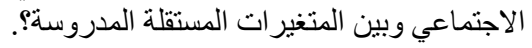

\section{أهداف البحث}

1- التعرف على الدور المنفذ للمنظمـات الدينيـة في في

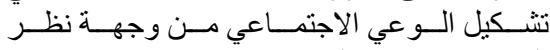
المبحوثين بمنطقة البحثي الاجئ.

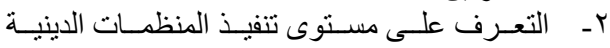

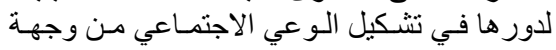
نظر المبحوثين بمنطقة البحثي.

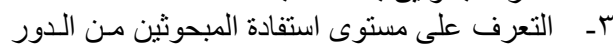

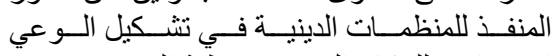

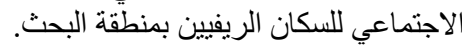

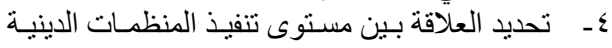

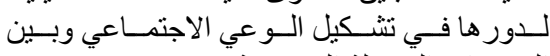
المتغير ات المستقلة المدروسية.

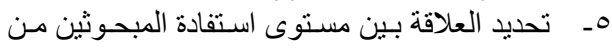

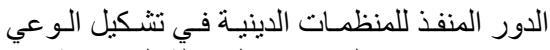

الاجتماعي وبين المتغيرات المستقلة المدروسة.

\section{التعاريف الإجرائية لبعض المصطلحات المستخدمة في البحث}

المنظمات الدينية: ويقصد بها في هذا البحث تلك المنظمات

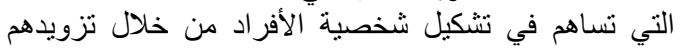

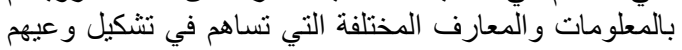

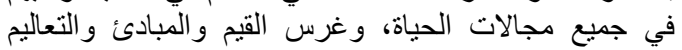

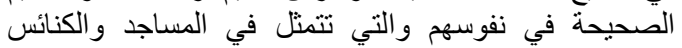
و الجمعيات ذات الطابع الديني.

الوعي الاجتماعي: ويقصد به في هذا البحث إدراكئ الكئ السكان

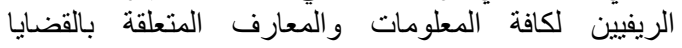
الاجتماعية السائدة بالمجتمع، والمشكاتلات التئ نواجه 
Ibrahim et al. / Archives of Agriculture Sciences Journal 4(2) 21-32, 2021.

جدول (1) : نوزيع شاملة وعينة البحث.

\begin{tabular}{|c|c|c|c|c|}
\hline عينة البحث & $\%$ & عدد الأسر (الثاملة) & القرى & المركز \\
\hline $7 Y$ & 0,17 & rova & المنشأة الكبرى & القوصية \\
\hline IYY & T,rY & 7997 & باقور & أبوتيج \\
\hline$\wedge \varepsilon$ & $\overline{Y, Y Y}$ & $\varepsilon \vee 9 \vee$ & عرب الأطاولة & الفتح \\
\hline rA & 9,9 & TITO & العز ايزة & الغنايم \\
\hline$V T$ & 1,19 & EIro & بنى حسين & أسبوط \\
\hline rVA & $\%$ & YITY & جمالى & \\
\hline
\end{tabular}

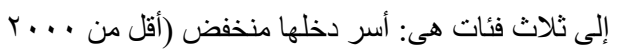

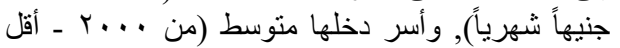

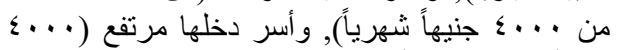

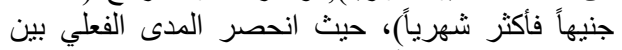
年

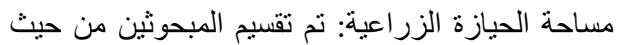

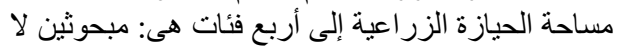

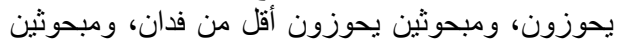

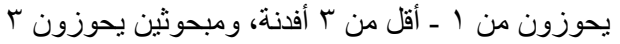

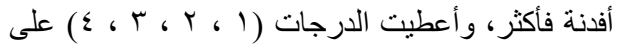

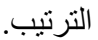

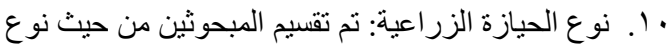

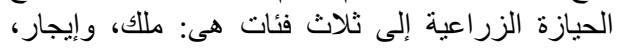

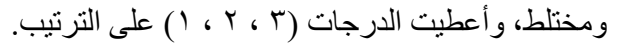

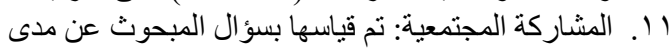

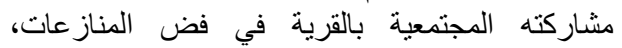

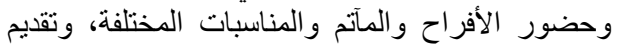

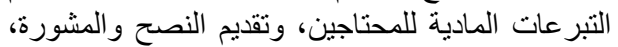

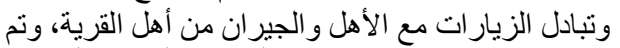

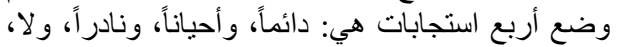

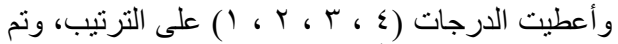
تقسيم المبحوثين وفقاً لمشاركتهم المجتمعية إلى ثلاث التهاث

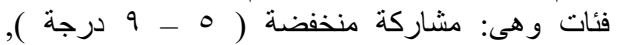

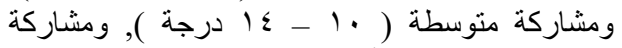
مرتفعة ( 10 درجة دأكثر)؛ حيثة حيث انحصر المدى الفعلي

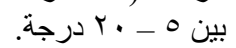
r ا. العضوية في المنظمات الريفية: تم قياسها بسؤال

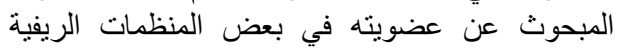

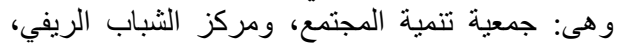

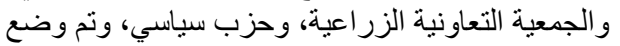

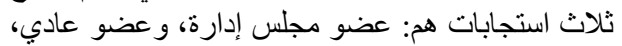

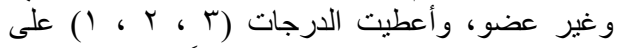

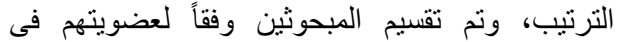

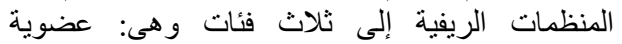

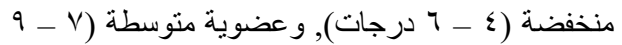

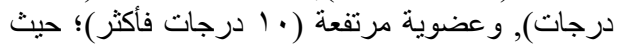
انحصر المدى الفعلي بين ـ - r ا أدرجة.

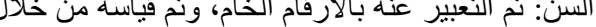

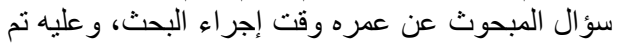

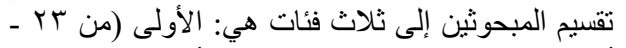

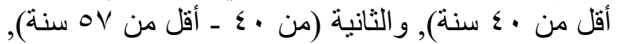

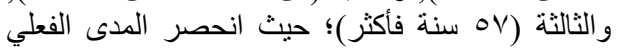

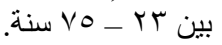
r. النوع: تم قياسه من خلال تقسيم المبحوثين إلى إلى نوعين:

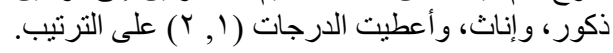

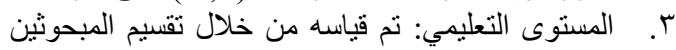

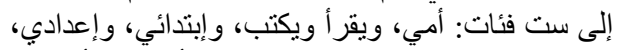

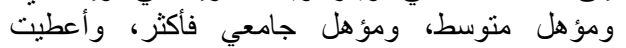

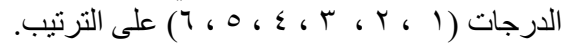

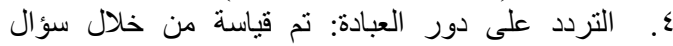

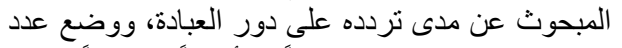

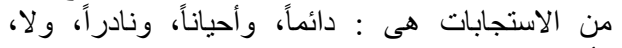

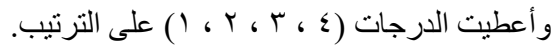

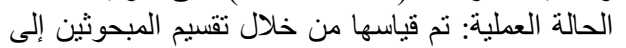

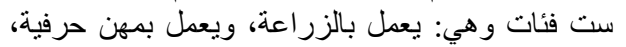

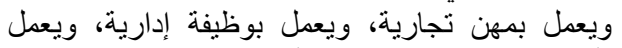

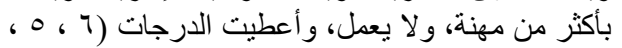

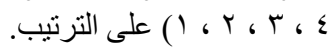
عدد أفراد الأسرة: تم التعبير الترثبير عنه بالأرقام الخام، وتم

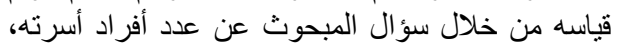

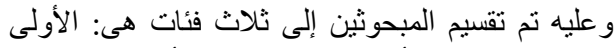

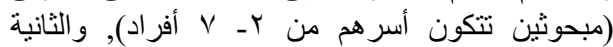

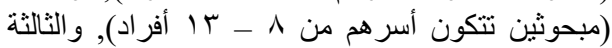

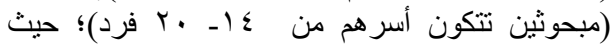

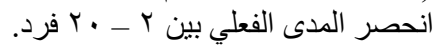

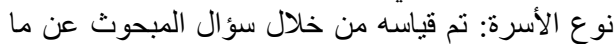

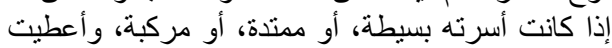

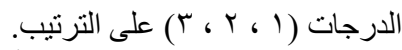

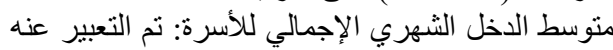

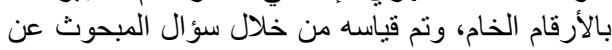

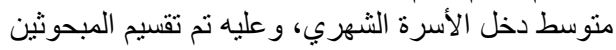




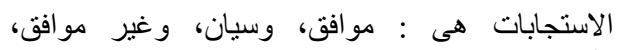

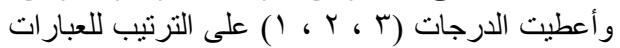

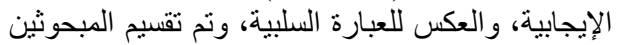

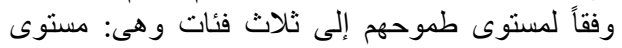

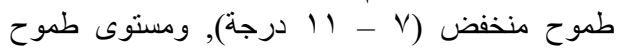

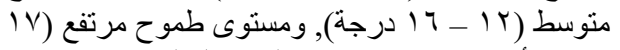

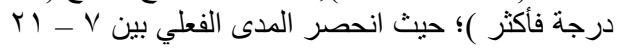

درجة. درجة

ثانياً: المتغير ات التابعة

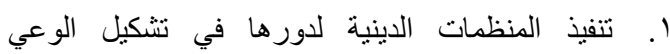

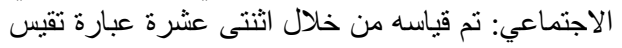

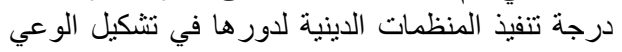

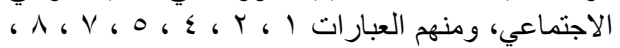

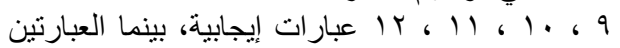

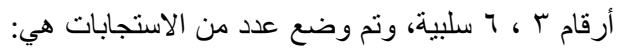

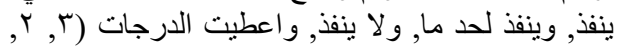
(1) على الترتيب في حالة العبار ات الايجابية و العكس في لاتي حالة العبار ات السلبية. r الاستفادة من الدور المنفذ للمنظمات الدينية في تشكيل

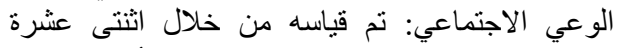

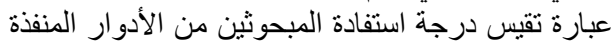

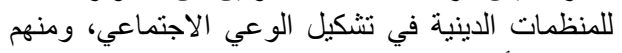

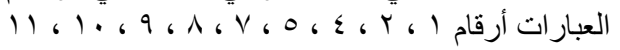

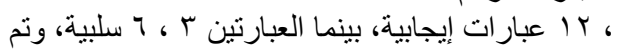

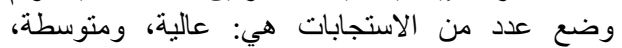

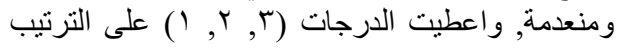
في حالة العبارات الايجابية والعكس في حالة العبات العبار الترتي

السلبية.

\section{أدوات التحليل الإحصائي}

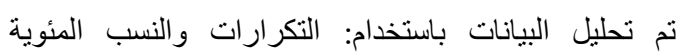

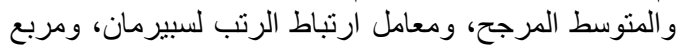

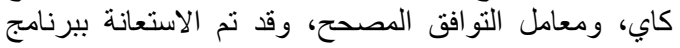

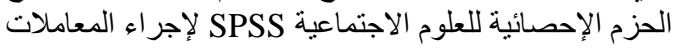

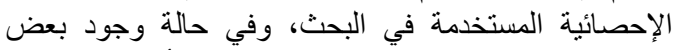

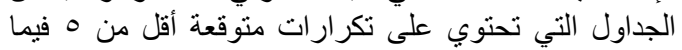

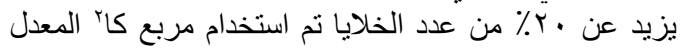

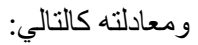

$\mathrm{X} 2=\sum\{(\mathrm{o}-\mathrm{e})-0.5\} 2 \div \mathrm{e}$

لـعامل التوافق المصح = ( معامل التوافق / م77, • ) rا. الانفتاح الثقافي: تم قياس هذا المتغير من خلال توجيه

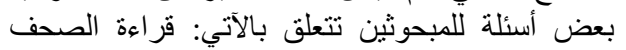

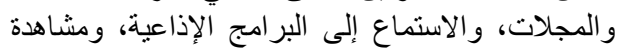

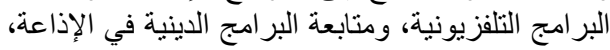

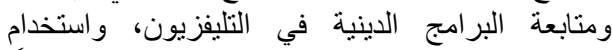

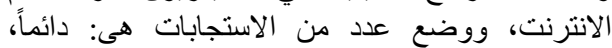

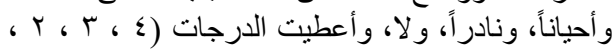

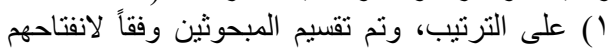
الثقافي إلى ثلاث فئات وهى:

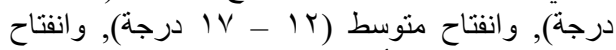

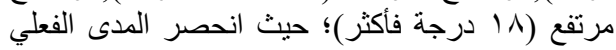

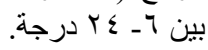

ـ ا. الانفتاح الخارجي: نم قياس هذا المتغير من خلال توجيه

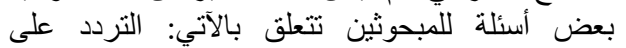

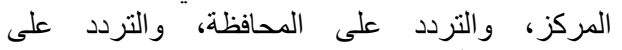

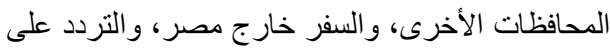

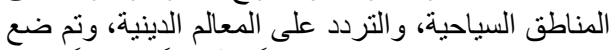

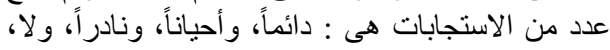

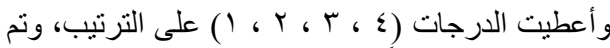

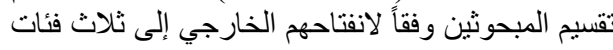

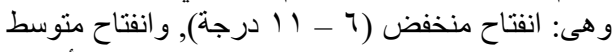

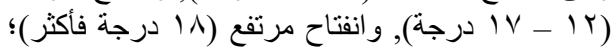

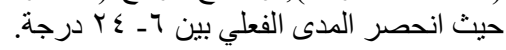

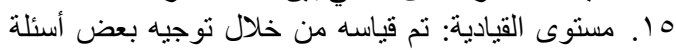

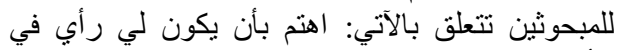

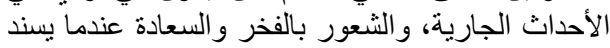

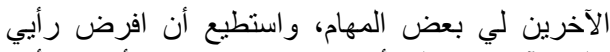

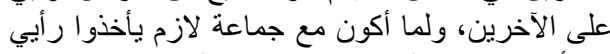

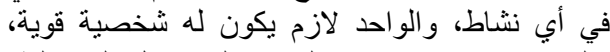
والو واحد لازم يكون عنده القدرة على على تحمل المسئولية،

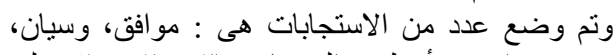

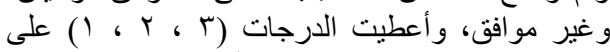

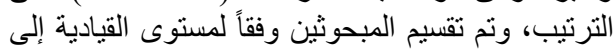

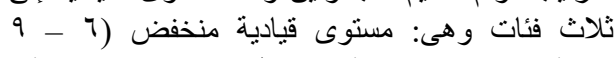

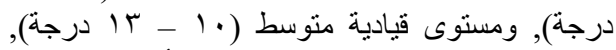

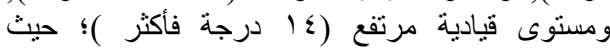

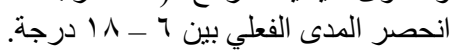

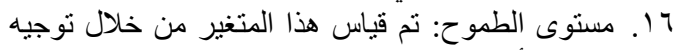

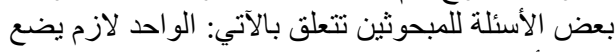

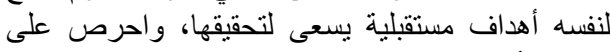

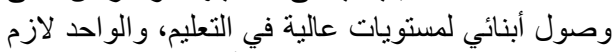

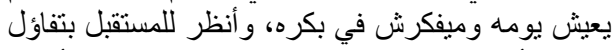

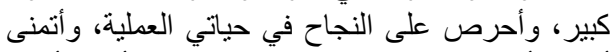

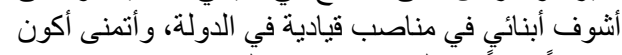

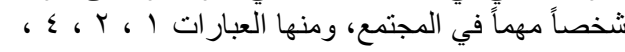

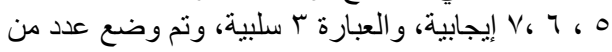




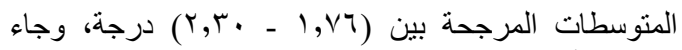

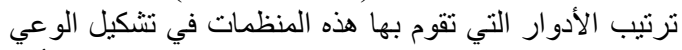

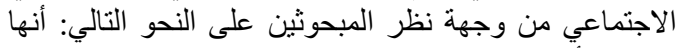

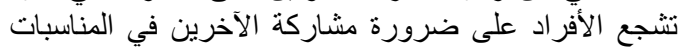

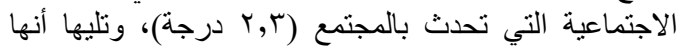

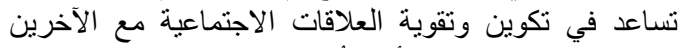

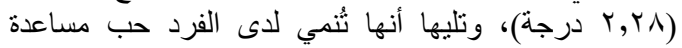

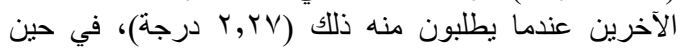
جاءت في المرتبة قبل الأخيرة أنها تحث على على دالى الاستعانة

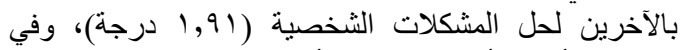

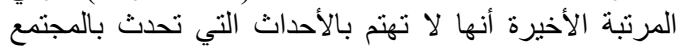

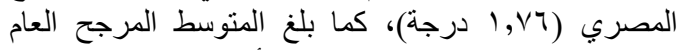

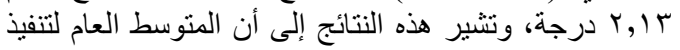

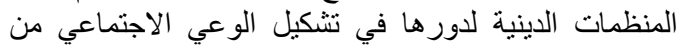
وجهة نظر المبحوثين يقع في فئة المتوسط.
النتائج ومناقشتها

أوعلا: التعرف على الدور المنفذ للمنظمات الدينية في تثكيل

اللتعرف على الدور المنفذ للمنظمات الدينية في تشكيل الوعي

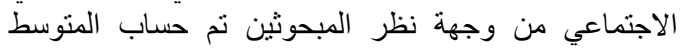

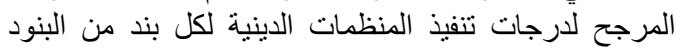

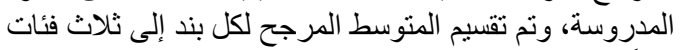

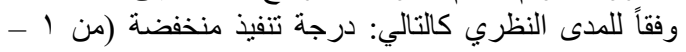



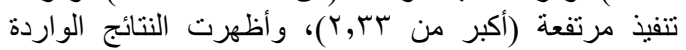

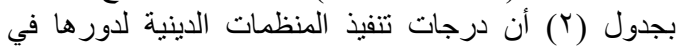

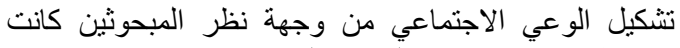

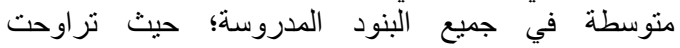

جدول (Y): التوزيع العددي و النسبي للمبحوثين وفقاً لتنفيذ المنظمات الدينية لدور ها في تثكيل الوعي الاجتماعي وفقاً لوجهة نظر هم مرتبة وفقاً للمنوسط

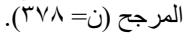

\begin{tabular}{|c|c|c|c|c|c|c|c|c|}
\hline \multirow{2}{*}{ الترتيب } & \multirow{2}{*}{ المتوسط المرجح } & \multicolumn{2}{|c|}{ لا ينفذ } & \multicolumn{2}{|c|}{ 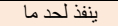 } & \multicolumn{2}{|c|}{ بينف } & \multirow{2}{*}{ الأدوار } \\
\hline & & $\%$ & عدد & $\%$ & عدد & $\%$ & عدد & \\
\hline 1 & ז,T. & 10,7 & 09 & rᄉ, & $1 \leq 7$ & $\sum 0, \wedge$ & $\operatorname{lVT}$ & تشجع الأفر اد على ضرورة مشاركة الآخرين في المناسبات الاجتماعية التي تحدث بالمجتمع \\
\hline r & Y, YA & $17, \varepsilon$ & 74 & rq, & $1 \leq 9$ & $\leqslant \leqslant, Y$ & $17 \mathrm{~V}$ & تساعد في تكوين وتقوية العلاقات الاجتماعية مع الآخرين \\
\hline$r$ & T,TV & 10,7 & 09 & $\leqslant 1, r$ & 107 & $\leqslant r, 1$ & $17 \pi$ & تُنمي لدى الفرد حب مساعدة الآخرين عندما يطلبون منه ذلك \\
\hline$\varepsilon$ & r, YT & 11,0 & $\mathrm{v} \cdot$ & $\xi \cdot, r$ & 104 & $\sum 1, r$ & 107 & تزود الأفر اد بمعلومات عن كيفية تتشئة أبنائهم تنشئئة اجتماعبة صحيحة \\
\hline o & r, r. & $T \cdot, \Sigma$ & VV & rq,9 & 101 & $r 9, \mathrm{r}$ & 10. & تنمي لدى الأفر اد حب الوطن وتشعر هم بأنهم جزء من المجتمع \\
\hline 7 & r, 19 & 19,7 & $v \leqslant$ & $\leqslant 1,0$ & $10 \mathrm{~V}$ & $r \wedge, q$ & $1 \leq V$ & تشجع الأفراد على ضرورة استغلال الوقت و عدم ضياعه فيما لا يفيد \\
\hline V & $r, 1 \wedge$ & $r r, \cdot$ & AV & ro,v & 1 To & $\varepsilon, r$ & 107 & تساهم في حل مشكلات الأفر اد وتعتبر ها واجب اجتماعي \\
\hline$\Lambda$ & r,IT & 19,9 & Vo & $\leqslant 7, \wedge$ & IVV & rt, & $1 \times 7$ & تساهم في جمع التبر عات لمساعدة الآخرين ت \\
\hline 9 & r,, & rt,O & 10 & $\leqslant \leqslant, \varepsilon$ & 171 & rt, & iro & تقدم مقترحات للتخلب على المشكلات المختلفة التي تظهر بالمجتمع \\
\hline 1. & r,, 1 & TV,O & $1 . \xi$ & $\varepsilon r, q$ & 177 & YA,T & 1.1 & تُكسب الأفراد المعرفة ببعض القضايا الاجتماعية السائدة بالمجتمع \\
\hline 11 & 1,91 & r9,1 & 11. & זT, & rio & $\mathrm{rV}, \hat{\Lambda}$ & $1 \leq 4$ & تحث على الاستعانة بالآخرين لحل المشكلات الشخصية \\
\hline Ir & $1, \sqrt{ }, 1$ & $r \cdot, 1$ & $\mathrm{VT}$ & rq, & 14 & $\leqslant r, q$ & 177 & لا تهتم بالأحداث التي تحدث بالمجتمع المصري \\
\hline
\end{tabular}

المصدر : استمار ات الاستبيان.

من المبحوثين يشيرون إلى أن مستوى تنفيذ المنظمات الدينية

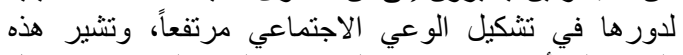

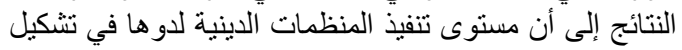

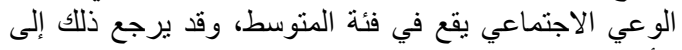

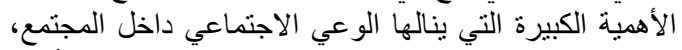

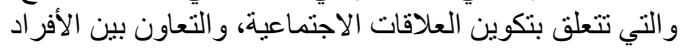

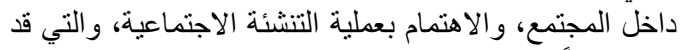

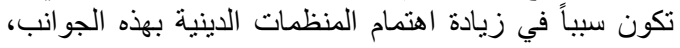
لخلق الإنسان القادر على المساهمة في بناء المجتمع وتقدمه.
ثانيا: التعرف على مستوى تتفيذ المنظمات الاينية لاورها في تثكيل الوعي الاجتماعي من وجهة نظر المبحوثين بمنطقة البحث

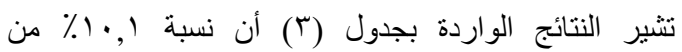

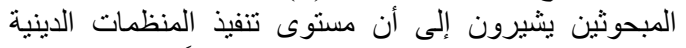

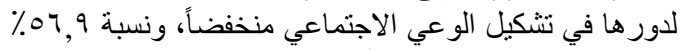

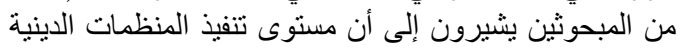

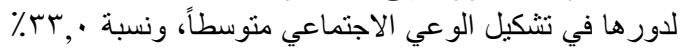

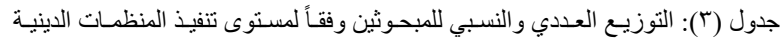

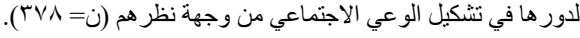

\begin{tabular}{|c|c|c|}
\hline$\%$ & العدد & مستوى تتفيذ المنظمات الدينية لدور ها في تشكيل الو عي الاجتماعي \\
\hline 1,1 . & ro & مستوى تنفيذ منخفض (r ( - • ب درجة) \\
\hline 9,07 & r 10 & مستوى تنفيذ متوسط ( Y _ Y Y درجة) \\
\hline . & iro & مستو ي تنفيذ مر تفع (9 ب درجة فأكثر) \\
\hline
\end{tabular}

المصدر : استمار ات الاستبيان. 


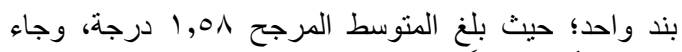

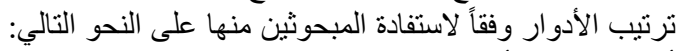

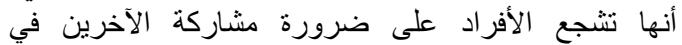

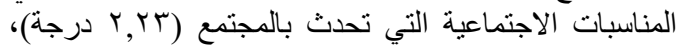

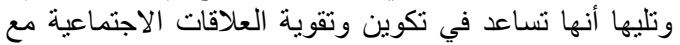

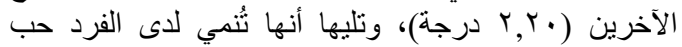

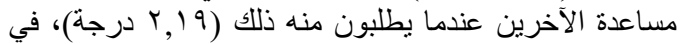



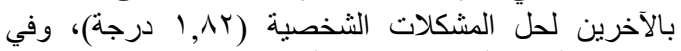

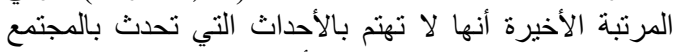



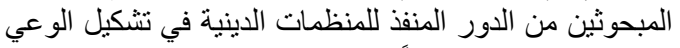

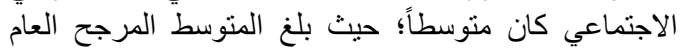

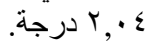

ثالثا: التعرف على مسنوى استفادة المبحوثين من الدور

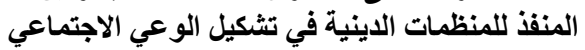

للتعرف على درجة استفادة المبحوثين من الدور المنفذ

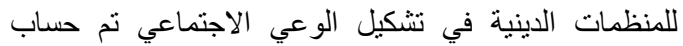

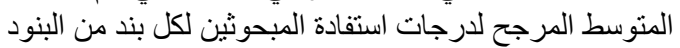

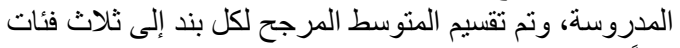

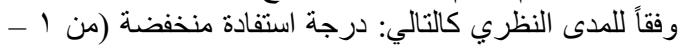

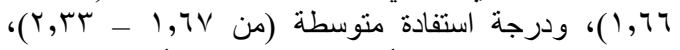

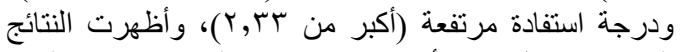

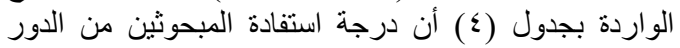

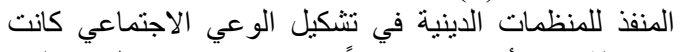

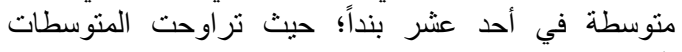



جدول (ع): التوزيع العددي و النسبي للمبحوثين وفقاً لاستفادتهم من الأدوار المنفذة للمنظمات الدينية في تثكيل الوعي الاجتماعي مرتبة وفقاً للمتوسط

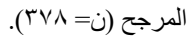

\begin{tabular}{|c|c|c|c|c|c|c|c|c|}
\hline \multirow{2}{*}{ الثرتيب } & \multirow{2}{*}{ المتوسط المرجح } & \multicolumn{2}{|c|}{ منعدمة } & \multicolumn{2}{|c|}{ متوسطة } & \multicolumn{2}{|c|}{ عالية } & \multirow{2}{*}{ الادوار } \\
\hline & & $\%$ & عدد & $\%$ & عدد & $\%$ & عدد & \\
\hline 1 & T, YT & IV,r & 70 & $\xi 1, \wedge$ & 101 & $\leqslant 1,{ }^{*}$ & 100 & تشجع الأفر اد على ضرورة مشاركة الآخرين في المناسبات الاجتماعية التي تحدث بالمجتمع \\
\hline r & r, t. & 19,7 & $\mathrm{~V} \xi$ & $\varepsilon \cdot, r$ & $10 \mathrm{r}$ & $\varepsilon \cdot, r$ & $10 \mathrm{r}$ & تساعد في تكوين وتقوية العلاقات الاجتماعية مع الآخرين \\
\hline 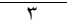 & 5,19 & $r \cdot, 1$ & $\mathrm{VT}$ & $\varepsilon \cdot, 0$ & 104 & rq, & $1 \leqslant 9$ & لُتُمي لاى الفرد حب مساعدة الآخرين عندما بطلبون منه ذلك \\
\hline$\leqslant$ & r,17 & rY,A & $\Lambda T$ & $r v, \Lambda$ & $1 \leqslant 4$ & r9, & $1 \leq 9$ & تزود الأفر اد بمعلومات عن كيفية تنشئة أبنائهم تنتشئة اجتماعية صحيحة \\
\hline 0 & r,11 & $r\urcorner, \wedge$ & 1.1 & $r 7, r$ & $1 \mathrm{TV}$ & $r v, \cdot$ & $1 \leq \cdot$ & تنمي لدى الأفر اد حب الوطن وتشعر هم بأنهم جزء من المجتمع \\
\hline 7 & r, 1 . & Y7, & $1 \cdots$ & $r\urcorner, \wedge$ & 149 & $r 7, \wedge$ & $1+9$ & تشجع الأفر اد على ضرورة استغلال الوقت و عدم ضياعه فيما لا يفيد \\
\hline $\mathrm{V}$ & $r, 99$ & TV,T & 1.4 & $\S 1,1$ & 101 & 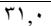 & $11 \mathrm{~V}$ & تتساهم في حل مشكلات الأفراد وتعتبر ها واجب اجتماعي \\
\hline$\Lambda$ & $r, \cdot \Lambda$ & r7,, $\mathrm{V}$ & 1.1 & $r \wedge, 1$ & $1 \leq \varepsilon$ & ro, r & $1 \mathrm{TH}$ & تساهم في جمع التبر عات لمساعدة الآخرين \\
\hline 9 & $r, \cdot V$ & $r V, \wedge$ & 1.0 & $r 7,0$ & $1 \pi \mathrm{A}$ & ro, $\mathrm{V}$ & iro & تقدم مقترحات للتخلب على المشكلات المختلفة التي تظهر بالمجتمع \\
\hline 1. & 1,90 & $r \cdot, r$ & $11 \leqslant$ & $\leqslant \leqslant, r$ & $17 \mathrm{~V}$ & ro, $\mathrm{V}$ & $9 V$ & تُكسب الأفراد المعرفة ببعض القضايا الاجتماعية الّائدة بالمجتمع \\
\hline 11 & $1, \wedge r$ & $r \leqslant, 7$ & $9 \pi$ & $r+r$ & $1 \times 4$ & $\sum r, 1$ & 109 & تحث على الاستعانة بالآخرين لحل المشكلات الشخصية \\
\hline ir & 1,01 & 14,0 & 01 & $r, r$ & 111 & $00, r$ & r.9 & لا تهتم بالأحداث التي تحدث بالمجتمع المصري \\
\hline & & & & & & & $\cdot \varepsilon=$ & المتوسط الم \\
\hline
\end{tabular}

المصدر: استمارة الاستبيان.

الاجتماعي مرتفعاً، وتشير هذه النتائج إلى أن مستوى استفادة

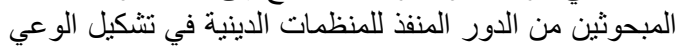

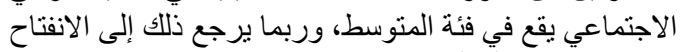

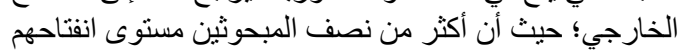

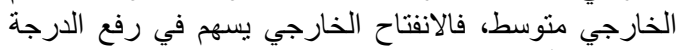

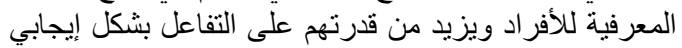

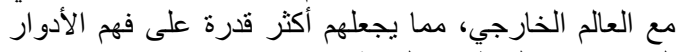
التي تقوم بها المنظمات الدينية و الاستفادة منها.

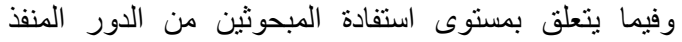
للمنظمات الدينية في تشكيل الوعي الاجتماعي فتشير النتائج

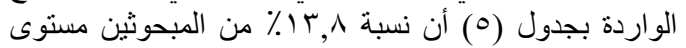

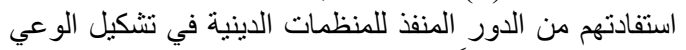

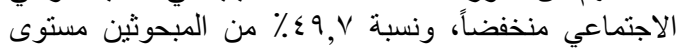

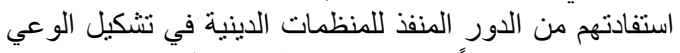

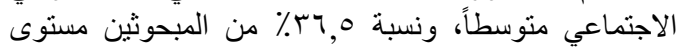

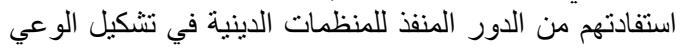

\begin{tabular}{|c|c|c|}
\hline$\%$ & العدد & مستوى تنفيذ المنظمات الدينية لدور ها في تشكيل الو عي الاجتماعي \\
\hline$\lambda, 1 \Gamma$ & or & مستوى تنفيذ منخفض (Y ( - •Y درجة) \\
\hline$v, \leqslant 9$ & $1 \mathrm{AN}$ & مستوى تنفيذ متوسط ( Y ـ ـ Y درجة) \\
\hline $0, \Gamma$ & $1 \mathrm{TN}$ & مستوى تنفيذ مرتفع (qج درجة فأكثر) \\
\hline
\end{tabular}


القيادية، ودرجة الطموح) (جدول رقم آ)، ومربع كابي بين

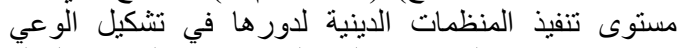

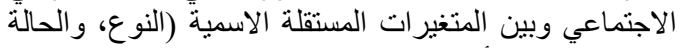

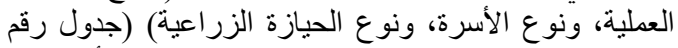

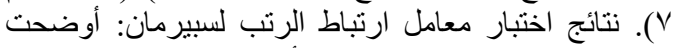

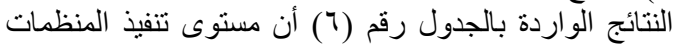

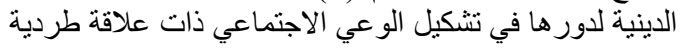

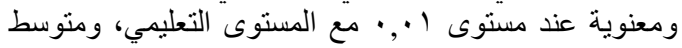

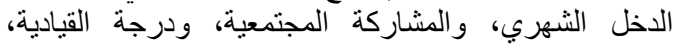

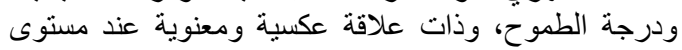

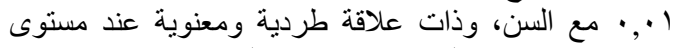

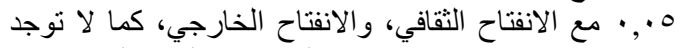

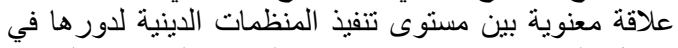

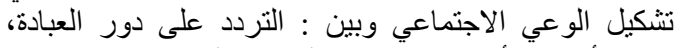

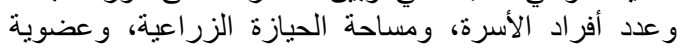

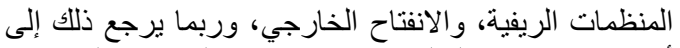

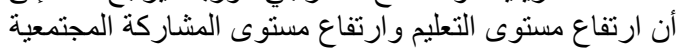

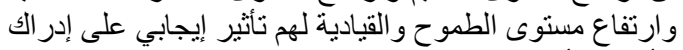
الأفراد للأدوار التي تقوم المنظمات الدينية بتنفيذها في تشكيل إلئيل

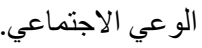

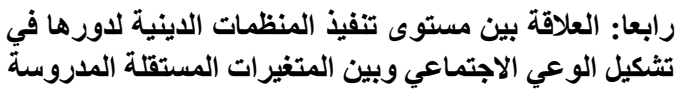

لتحديد العلاقة بين مستوى تتفيذ المنظمات الدينية لدور ها في المئي

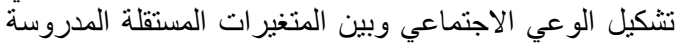

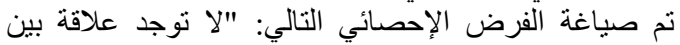

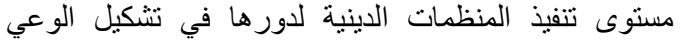

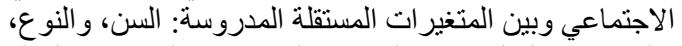

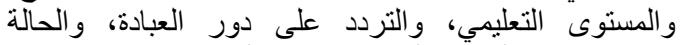

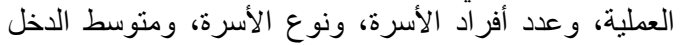

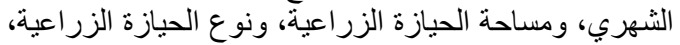

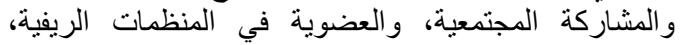

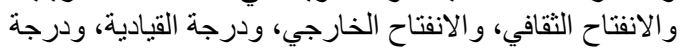

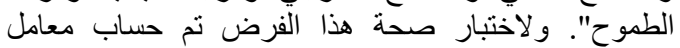
إرتباط الرتب لسبيرمان بين مستوى تلفيذ المنيذ المنظمات الدينية

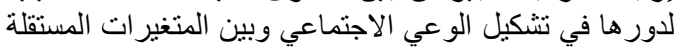

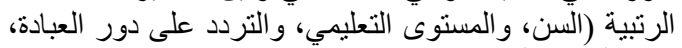

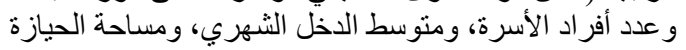

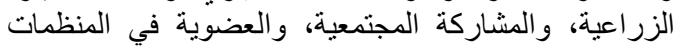

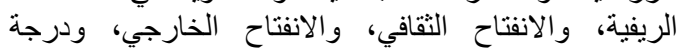

جدول (†): نتائج اختبار معامل ارتباط الرتب لسبيرمان بين مستوى تنفيذ المنظمـات الدينيـة لدور ها في

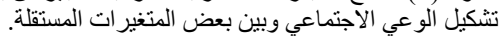

\begin{tabular}{|c|c|}
\hline قيم معامل الارنباط & المتغير ات المستقلة \\
\hline **., 10\%- & السن \\
\hline$* *, 171$ & المستوى التعليمي \\
\hline ,,$Y Y$ & التردد على دور العبادة \\
\hline., $0 \varepsilon_{-}$ & عدد أفر اد الأسرة \\
\hline$* *, 1 \leqslant 1$ & متوسط الدخل الثهربي \\
\hline .,.,Tr- & مساحة الحيازة الزر اعية \\
\hline **,ITr & المشاركة المجتمعية \\
\hline.,.$T O_{-}$ & عضوية المنظمات الريفية \\
\hline$*, \| T$ & الانفتاح الثقافي \\
\hline , & الانفتاح الخارجي \\
\hline$* *, r \mid r$ & درجة القيادية \\
\hline$* *, r q 1$ & درجة الطموح \\
\hline
\end{tabular}

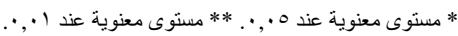

جدول (V): قيم مريع كاي بين مستوى تنفيذ المنظمات الدينية لدور ها في تثكيل الوعي الاجتماعي وبين بعض المتغير ات المستقلة.

\begin{tabular}{|c|c|c|c|}
\hline درجة الحرية & معامل التو افق المصحح & قيم كاי & المتغير ات المستقلة \\
\hline$r$ & & $1.9, r$ & نوع المبحوث \\
\hline 1. & & $\cdot \varepsilon Y, Y$ & الحالة العملية \\
\hline$\varepsilon$ & $1 \wedge \varepsilon$, & $9.7, * 9$ & نوع الأسرة \\
\hline 7 & YIT, & VAr,*IT & نوع الحيازة الزر اعية \\
\hline
\end{tabular}

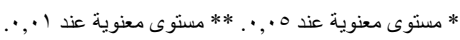

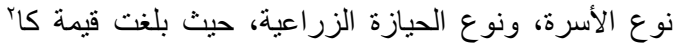

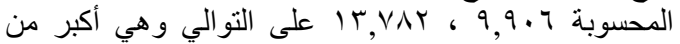
نظيرتها الجدولية. ولتحديد شدة العلاقة بين مسنوى تنفيذ
نتائج اختبار مربع كاي: أوضحت النتائج الواردة بالجدول رقم

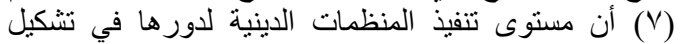

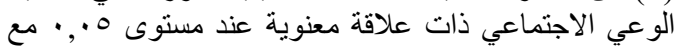


الخارجي، ودرجة القيادية، ودرجة الطموح". و لاختبار صحة إنبان

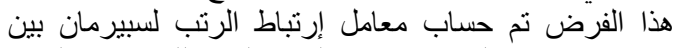

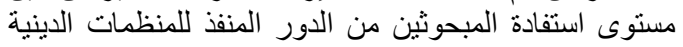

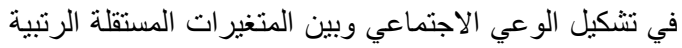

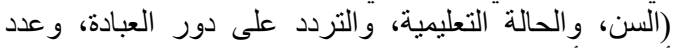

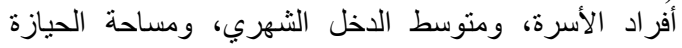

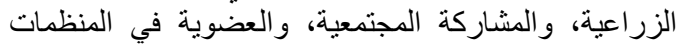

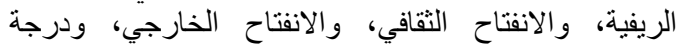

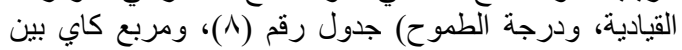

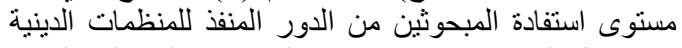

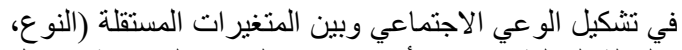

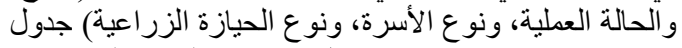

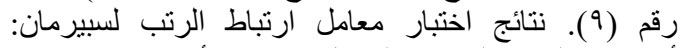

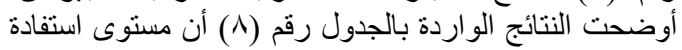

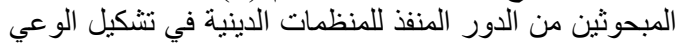

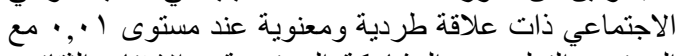

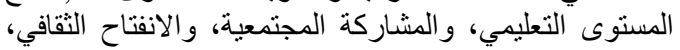

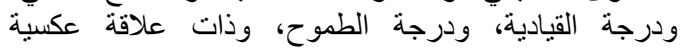

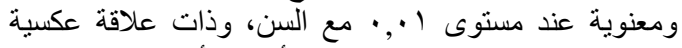

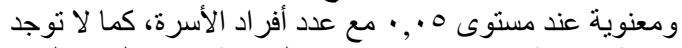

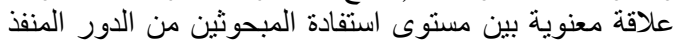

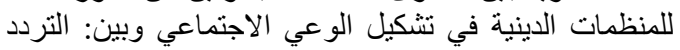

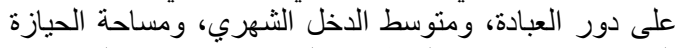

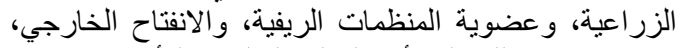

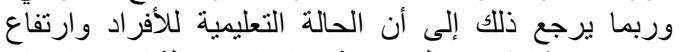

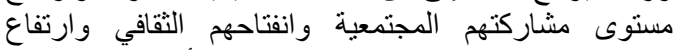
مستوى الطموح و القيادية لديهم تعتبر من أهم العواملية التهائ التي

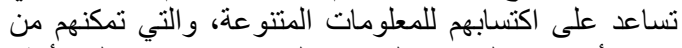

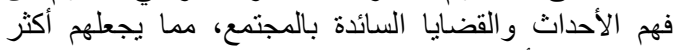
استفادة من الأدوار التي تقدم إليهم.
المنظمات الدينية لدورها في تشكيل الوعي الاجتماعي وبين

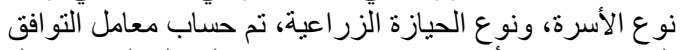

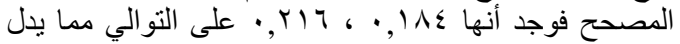

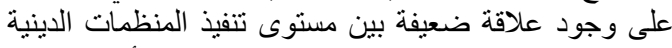

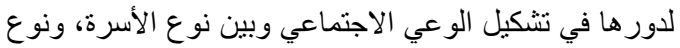

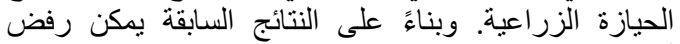

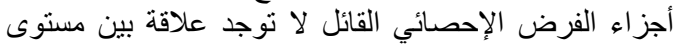

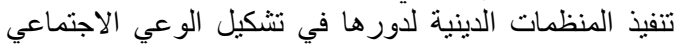

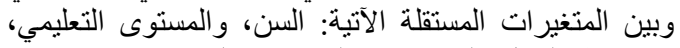



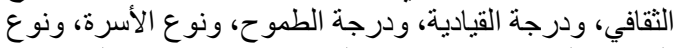

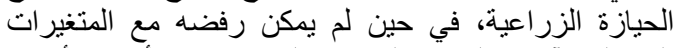

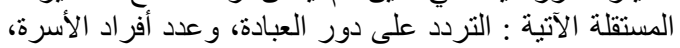

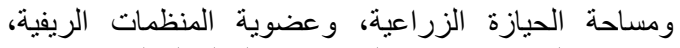
والانفتاح الخارجي، ونوع المبحوث، و الحالة اعلةو العملية.

خامسا: العلاقة بين مستوى استفادة المبحوثين من الدور

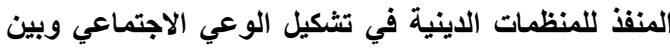

المتغير ات المستقلة المدروسئة المئة فئة

لتحديد العلاقة بين مستوى استفادة المبحوثين من الدور المنفذ

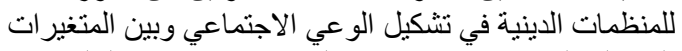

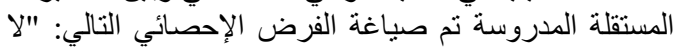

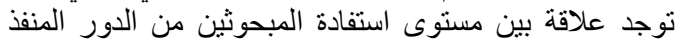

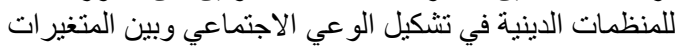

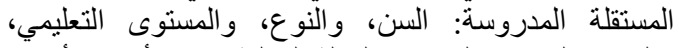

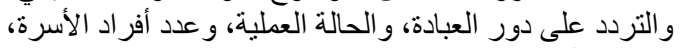

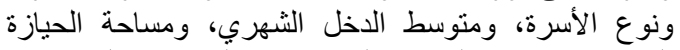

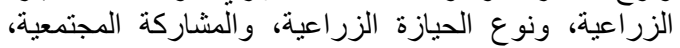

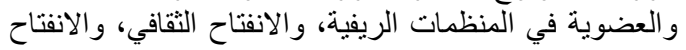

\begin{tabular}{|c|c|}
\hline قيم معامل الارتباط & المتغير ات المستقلة \\
\hline$* * ., 197$ & السن \\
\hline$* *, 1 \leq r$ & المستوى التعليمي \\
\hline , ro & التردد على دور العبادة \\
\hline$* ., 1,0_{-}$ & عدد أفر اد الأسرة \\
\hline,$\wedge 7$ & متوسط الدخل الثهري \\
\hline., $.9 Y_{-}$ & مساحة الحيازة الزر اعية \\
\hline$* *, 10$ & المشاركة المجتمعية \\
\hline.,$+7 \varepsilon_{-}$ & عضوية المنظمات الريفية \\
\hline$* *, 109$ & الانفتاح الثقافي \\
\hline , & الانفتاح الخارجي \\
\hline$* *, r Y q$ & درجة القيادية \\
\hline$* *, r \leqslant r$ & درجة الطموح \\
\hline
\end{tabular}

* مستوى معنوية عند 0., . . ** مستوى معنوية عند ا +,.•. 
Ibrahim et al. / Archives of Agriculture Sciences Journal 4(2) 21-32, 2021.

\begin{tabular}{|c|c|c|c|c|}
\hline درجة الحرية & معامل التو افق المصحح & قيم كا’ المعدل & قيم كاי & المتغير ات المستقلة \\
\hline$r$ & & - & $794, r$ & نوع المبحوث \\
\hline 1. & r^१, & - & $770, * *$ Yo & الحالة العملية \\
\hline$\varepsilon$ & & $\cdot V V, r$ & - & نوع الأسرة \\
\hline 7 & TrV, & - & YMI,*10 & نوع الحيازة الزر اعية \\
\hline
\end{tabular}

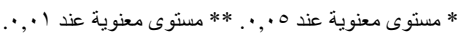

المستوى التعليمي للمبحوثين وبين مستوى

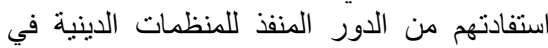

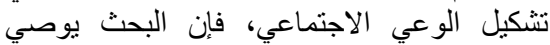

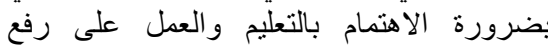

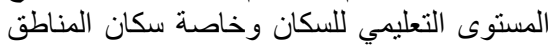

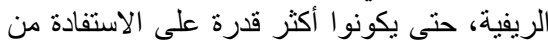
الأدوار التي تقدم إليهم.

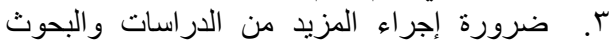

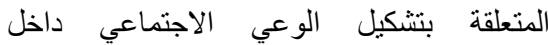
المجتمعات الريفية لتكون نتائجها منطلقاً لتخطيط التئي البرامج التي تهدف إلى رفع مستوى البن الوعي داخل

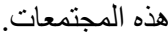

قائمة المراجع

\section{مراجع باللغة العربية}

إبر اهيم عبد الرحمن خليفة ، محمد محمد إسماعيل عبد الحافظ الإني

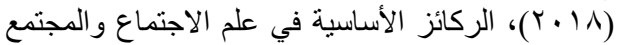

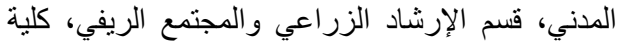

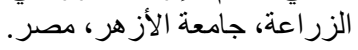

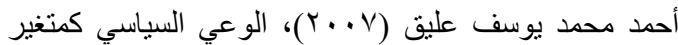

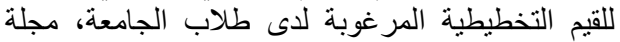

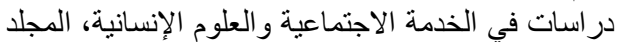

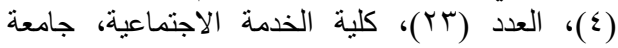
حلوان، مصر. العرد

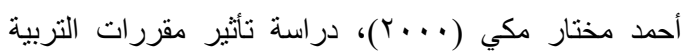

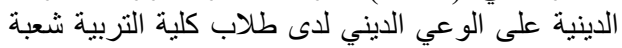

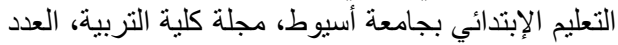

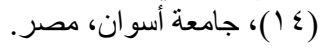

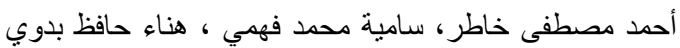

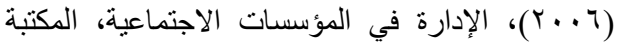

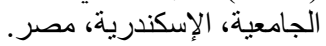

نتائج اختبار مربع كاي: أوضحت النتائج الواردة بالجدول رقم

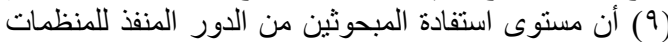

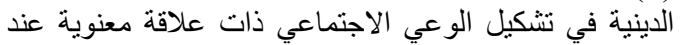

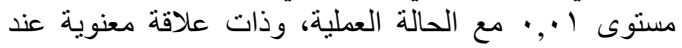

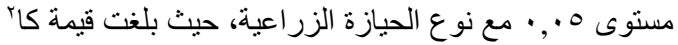

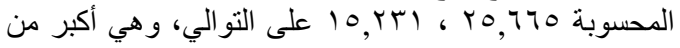

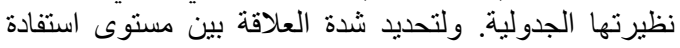

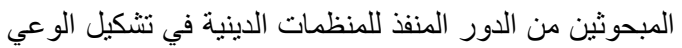

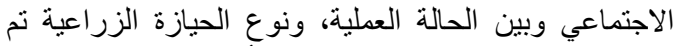

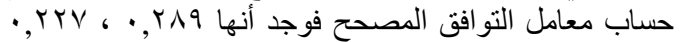

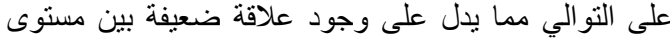
استفادة المبحوثين من الدور المنفذ للمنظمات الدئي الدينية في تشكيل

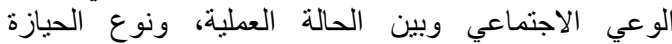

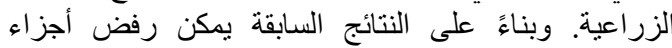

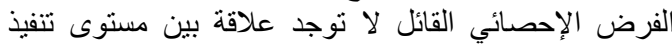

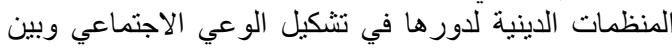

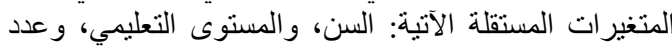

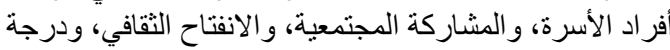

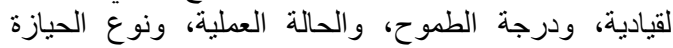

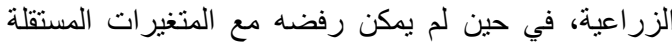

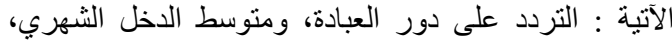

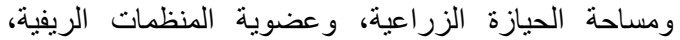
و الانفتاح الخارجي، ونوع المبحة ألموث، ونوع الأسرة.

\section{توصيات البحث}

استناداً إلى نتائج البحث يمكن اقتر اح التوصيات التالية:

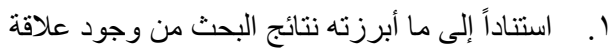

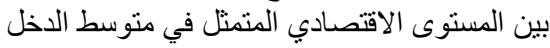

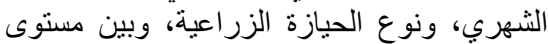

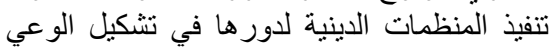

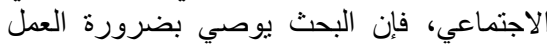

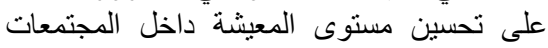

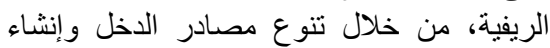

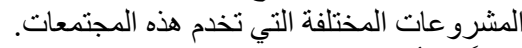

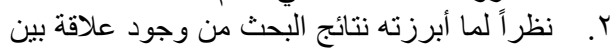




$$
\begin{aligned}
& \text { الاجتماعية والعلوم الإنسانية، المجلد (1)، العدد (·) (ب)، } \\
& \text { كلية الخدمة الاجتماعية، جامعة حلو الإنه، مصرة المجر }
\end{aligned}
$$

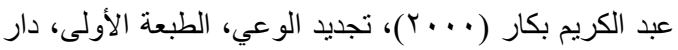

$$
\begin{aligned}
& \text { القلم، دمشق، سوريا. } \\
& \text { عبد الهادي الجوهري (1 . . ب)، أصول علم الاجتماع، المكتبة }
\end{aligned}
$$

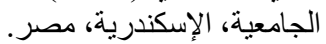

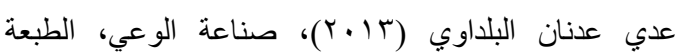

$$
\begin{aligned}
& \text { الأولى، مؤسسة البلداوي للطباعة، العراق. }
\end{aligned}
$$

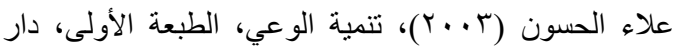

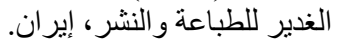

$$
\begin{aligned}
& \text { فتحي محمد أبوعيانة ( . . . . )، دراسات في علم السكان، دار }
\end{aligned}
$$

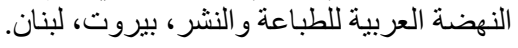

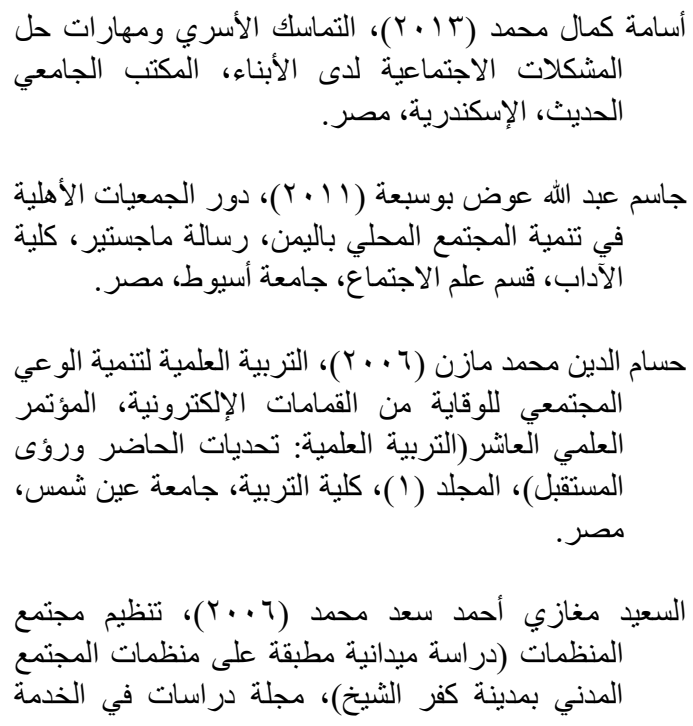

\section{مراجع باللغة الانجليزية}

Hinings, C. R. and Raynard, Mia (2014), Organizational from structure and religious organizations, Research in the sociology of organizations, Vol. 41, Emerald Group, U.K.

Krejcie, V. and Morgan D. W. (1970), "Determining sample size for research activities", Educational and Psychological Measurement, Vol. 30, pp. 607-610.
Moyer, J., Sinclair, A. and Spaling, H. (2012), "Working for God and Sustainability: The Activities of Faith-Based Organizations in Kenya", VOLUNTAS: International Journal of Voluntary and Nonprofit Organizations, Vol. 23, Article ID:10.1007/s11266-011-9245-x. 